\title{
Spectrum of Heart Diseases at a Referral Tertiary Care Hospital in Somalia, Mogadishu: An Echocardiographic Study
}

Gökhan Alıcı ( $\square$ gokhan_alici1@hotmail.com)

Somalia Mogadishu Training and Research Hospital

Ömer Genç

MD,Agri Training and Research Hospital

Research Article

Keywords: Congenital heart disease, rheumatic heart disease, Somalia, hypertensive heart disease

Posted Date: September 20th, 2021

DOI: https://doi.org/10.21203/rs.3.rs-832429/v1

License: (c) This work is licensed under a Creative Commons Attribution 4.0 International License. Read Full License 


\section{Abstract}

Background: To investigate the frequencies and patterns of cardiovascular diseases (CVD), including rheumatic and congenital heart diseases, assessed by echocardiographic examinations in the only referral tertiary care hospital in Mogadishu, the capital of Somalia.

Methods: This retrospective, descriptive registry reviewed the pathological echocardiographic findings of 1140 patients aged 0-100 years who were admitted to the cardiology outpatient clinic in a tertiary training hospital in Mogadishu.

Results: Hypertensive heart disease (HHD) 454 (39.8\%) and degenerative valvular disease 395 (34.6\%) were the most common comorbidities. Congenital heart diseases (CHD) were detected in 151 (13.2\%) of the patients, with the most common ones including atrial septal defect (ASD) 37 (3.2\%) and ventricular septal defect (VSD) 26 (2.3\%).Rheumatic heart disease (RHD) was detected in 84 (7.4\%) patients, among whom the most common age range was $16-30$ years $(40.5 \%)$, followed by $31-45$ years $(31 \%)$ and $0-15$ years $(15.5 \%)$.

Conclusion: In the present study, we found that HHD was the most common comorbidity , followed by degenerative valvular disease, Heart failure with reduced ejection fraction(HFrEF), and Ischemic heart disease(IHD).Moreover, the most common valvular disease was mitral insufficiency and the most common CHD was ASD.

\section{Introduction}

Cardiovascular diseases (CVDs) are the leading cause of death worldwide[1].Its frequency, treatment options, subgroups including congenital heart diseases (CHDs), and outcomes have been well documented in developed countries so far. However, there are still serious concerns regarding the quality and reliability of available data in low-middle-income countries. According to the World Health Organization, CVDs are the second most common cause of overall mortality in Africa, and further supporting this conclusion, 1.2 million people worldwide died from CVDs in 2015[2]. In addition to CHDs, which have a relatively similar distribution all over the world, rheumatic heart disease (RHD), secondary to noncommunicable diseases, is also naturally preventable and another leading cause of poor outcomes in low-middle income developing countries[3].Every year, 291,000 deaths, accounting for $2 \%$ of CVD deaths, occur due to RHD[4].

Even though echocardiography is an easy-to-use, inexpensive, non-invasive, and reliable ultrasound-based modality, its use in many parts of Africa is still highly limited[5].Therefore, there is a lack of reliable data on diagnosis, follow-up, treatment, and prevention of CVDs in those regions. Moreover, this drawback is considered to be a crucial and noteworthy challenge in reducing preventable non-communicable diseases in lowmiddle-income countries. To this end, the present study sought to address the frequency and pattern of CVDs assessed by echocardiographic examinations in Mogadishu, the capital of Somalia.

\section{Patients And Methods}

\section{Study population and design}

This retrospective, descriptive and observational registry reviewed the echocardiographic findings of patients aged 0-100 years who were presented to our outpatient cardiology clinic at a tertiary training hospital in Mogadishu, between January 1, 2019, and January 1, 2020. Overall, 6782 subjects admitted to the hospital were reviewed. 5642 individuals who had incomplete, unreliable data and/or those with completely normal echocardiographic findings were extracted from the study. Accordingly, a total of 1140 patients with pathological echocardiographic findings were enrolled in the study. Demographic characteristics and echocardiographic parameters including ejection fraction (EF), interventricular septum (IVS) thickness, left ventricular (LV) diastolic dysfunction grade, mitral valve insufficiency/stenosis, and degenerative, rheumatic, and congenital heart diseases were analyzed for each participant. Echocardiographic evaluations were performed by experienced echocardiographers who were licensed in Turkey using a Toshiba Aplio ${ }^{\mathrm{TM}}$ ultrasound system (TUS-A500, Shimoishigami, Japan) in accordance with the American Society of Echocardiography guidelines[6].Those aged 15 and under were defined as a child. Age- and gender-based distributions of acquired, congenital, and rheumatic heart diseases were evaluated. Those with active tuberculosis or a history of TB were evaluated together, regardless of whether they received treatment or not. The study was conducted according to the Helsinki Declaration. Ethical approval was obtained from the local ethics committee (date:17.02.2021,decision no:323). The need for informed consent was waived due to the retrospective nature of the study.

Hypertensive heart disease (HHD) was diagnosed in the presence of signs of heart failure or criteria for left ventricular hypertrophy (LVH) on electrocardiography (ECG) or echocardiography, considered not to be caused by valvular heart disease (VHD) and/or ischemic heart disease (IHD), for known or newly diagnosed hypertensive patients (TA>140/90 mmHg), regardless of systolic or diastolic dysfunction.

Valvular heart disease (VHD) was defined as an obvious function and size abnormality, insufficiency/stenosis, abnormal thickening of valve leaflets or cusps, coaptation failure, calcification, and loss of normal contour detected by echocardiography in at least one of the heart valves.

Rheumatic heart disease (RHD) was diagnosed in accordance with the 2012 World Heart Federation (WHF) criteria for echocardiographic diagnosis of RHD[7]. 
Ischemic heart disease (IHD) was diagnosed in patients with a history of angina pectoris or a history of myocardial infarction, or an ECG feature indicating a previous myocardial infarction and a regional wall motion abnormality suggestive of myocardial infarction detected on echocardiography.

Dilated cardiomyopathy (DCM) was defined as left ventricular or biventricular systolic dysfunction and dilatation (left ventricular end-diastolic diameter $>58 \mathrm{~mm}$ for males and $>52 \mathrm{~mm}$ for females), not explained by abnormal filling conditions or coronary artery disease, regardless of being primary or secondary[8].

Hypertrophic cardiomyopathy (HCM) was defined as unexplained maximal wall thickness $>15$ mm in any left ventricular myocardial segment or presence of left ventricular septal/posterior wall thickness ratio > 1.3 in normotensive patients and > 1.5 in hypertensive patients[9, 10].Since HCM patients in our study were adults, both thresholds were applied to all of them.

Pericardial effusion (PE) was diagnosed in the presence of an echo-freespace between the visceral and the parietalpericardium. The classification was as follows: $\mathrm{mild}(<10 \mathrm{~mm})$, moderate $(10-20 \mathrm{~mm})$, and severe $(>20 \mathrm{~mm})$.

Constrictive pericarditis was diagnosed in the presence of echocardiographic signs of constriction characterized by a thickened, fibrotic pericardium, limiting the heart's ability to function normally.

Heart failure with reduced EF (HFrEF) was diagnosed in the presence of clinical signs of heart failure, along with a reduced EF of $<\% 50$ assessed by echocardiography.

Pulmonary arterial hypertension was defined as the presence of systolic pulmonary artery pressure (SPAP) $\geq 2.8 \mathrm{~m} / \mathrm{sec}$ or $\geq 36 \mathrm{mmHg}$ on echocardiography, in addition to symptoms and other findings that are associated with pulmonary hypertension(11).

\section{Statistical analysis}

Statistical analyses were performed using IBM SPSS Statistics for Windows Version 20.0 (Armonk, NY: IBM Corp.). The normality of continuous variables was assessed by analytical (Kolmogorov-Smirnov test) and visual methods (histograms and probability plots). Continuous variables were expressed as median (interquartile range [IQR]) only due to the presence of abnormal distribution for all.Categorical variables were expressed as numbers ( $\mathrm{n}$ ) and percentages (\%). Continuous variables were compared using the Mann-Whitney $U$ test and categorical variables were compared using the $\chi 2$-test or Fisher's exact test, where appropriate.A two-tailed $p$-value of $<0.05$ was considered significant throughout the study.

\section{Results}

Out of the study population with a total of 1140 participants, 646 (56.7\%) were male, the median age was 60 (IQR; $42-70)$ years and 113 (9.9\%) were children.Children were more likely to be female $(p=0.045)$. HHD was found to be the most common comorbidity $454(39.8 \%)$, followed by VHD 395 (34.6\%), HFrEF 351 (30.8\%), and IHD 278 (24.4\%).RHD was detected in 84 (7.4\%) patients. The most observed age range in patients with RHD was $16-30$ years 461 (40.5\%), followed by $31-45$ years $387(31 \%)$, and $0-15$ years $176(15.5 \%)$ (Fig. 2). While the number of patients with a history of tuberculosis or active tuberculosis was 202 (17.7\%), 9 (0.8\%) subjects were diagnosed with constrictive pericarditis due to any reason.Of the participants, 244 (21.4\%) had DCM. Detailed demographic characteristics of the study population are listed in Table 1. 
Table 1

Demographic characteristics of the study population by gender

\begin{tabular}{|lllll|}
\hline Variables & All & Male & Female & p-value \\
\hline Age, years & $60(42-70)$ & $61(47-71)$ & $60(35-70)$ & 0.002 \\
\hline Child, $\mathbf{n}(\%)$ & $113(9.9)$ & $54(8.4)$ & $59(11.9)$ & 0.045 \\
\hline Diabetes mellitus, $\mathbf{n}(\%)$ & $263(23.1)$ & $183(28.3)$ & $80(16.2)$ & 0.021 \\
\hline Hypertensive heart failure, $\mathbf{n}(\%)$ & $454(39.8)$ & $274(42.4)$ & $180(36.4)$ & 0.035 \\
\hline Current smoker, $\mathbf{n}(\%)$ & $57(5)$ & $26(4.0)$ & $31(6.3)$ & 0.404 \\
\hline Ischemic heart disease, $\mathbf{n}(\%)$ & $278(24.4)$ & $206(31.9)$ & $72(14.5)$ & $<0.001$ \\
\hline Heart failure with reduced EF, $\mathbf{n}(\%)$ & $351(30.8)$ & $237(36.7)$ & $114(23.1)$ & $<0.001$ \\
\hline Valvular heart disease, $\mathbf{n}(\%)$ & $395(34.6)$ & $161(32.6)$ & $234(36.2)$ & 0.199 \\
\hline Rheumatic heart disease, $\mathbf{n}(\%)$ & $84(7.4)$ & $30(4.6)$ & $54(10.9)$ & $<0.001$ \\
\hline Congenital heart disease, $\mathbf{n}(\%)$ & $151(13.2)$ & $71(10.9)$ & $80(16.2)$ & 0.009 \\
\hline Pulmonary arterial hypertension, $\mathbf{n}(\%)$ & $260(22.8)$ & $150(23.2)$ & $110(22.3)$ & 0.745 \\
\hline CoPD, $\mathbf{n}(\%)$ & $66(5.8)$ & $13(2)$ & $53(10.7)$ & 0.004 \\
\hline Dilated cardiomyopathy, $\mathbf{n}(\%)$ & $244(21.4)$ & $173(26.8)$ & $71(14.4)$ & $<0.001$ \\
\hline Constrictive pericarditis, $\mathbf{n}(\%)$ & $9(0.8)$ & $7(1.1)$ & $2(0.4)$ & 0.202 \\
\hline Peripartum cardiomyopathy, $\mathbf{n}(\%)$ & $21(1.8)$ & - & $21(1.8)$ & - \\
\hline Tuberculosis, $\mathbf{n}$ (\%) & $202(17.7)$ & $104(16.1)$ & $98(19.8)$ & 0.438 \\
\hline
\end{tabular}

Median EF was 60\% (IQR:40-65).There were 182 (15.9\%) subjects with grade II-IV diastolic dysfunction.Mitral insufficiency 541 (47.5\%) was detected as the most common VHD, followed by aortic insufficiency 437 (38.3\%), and tricuspid insufficiency 264 (23.2\%) and mitral valve stenosis 39 (3.4\%) was the least common VHD (Table 2). On the other hand, 151 (13.2\%) patients had CHDs, of which 23 (15.2\% of CHDs) were cyanotic CHDs. The most frequent CHD was atrial septal defect (ASD) 37 (3.2\%), followed by ventricular septal defect(VSD) 26 (2.3\%) and patent ductus arteriosus (PDA) 25 (2.2\%) (Fig. 1a).ASD was observed to be more common in females, whereas VSD and PDA had a similar frequency across genders (Fig. 1b). The most frequent age group with CHD cases was $0-15$ years 770 (67.5\%), followed by 16-30 years 219 (19.2\%) (Table 3 ). 
Table 2

Echocardiographic findings of the study population by gender

\begin{tabular}{|c|c|c|c|c|}
\hline Variables & $\begin{array}{l}A / I \\
(n: 1140)\end{array}$ & $\begin{array}{l}\text { Male } \\
(n: 646)\end{array}$ & Female (n:494) & $p$ \\
\hline Ejection fraction, \% & $60(40-65)$ & $55(35-60)$ & $60(55-65)$ & $<0.001$ \\
\hline Interventricular septum thickness, mm & $11(10-14)$ & $13(10-14)$ & $11(10-14)$ & 0.001 \\
\hline LV diastolic dysfunction and grades, $n(\%)$ & $668(58.6)$ & $416(64.4)$ & $252(51.0)$ & $<0.001$ \\
\hline Grade I & $486(42.6)$ & $289(44.7)$ & $197(39.9)$ & \\
\hline Grade II & $141(12.4)$ & $99(15.3)$ & $42(8.5)$ & \\
\hline Grade III & $34(2.9)$ & $23(3.6)$ & $11(2.2)$ & \\
\hline Grade IV & $7(0.6)$ & $5(0.8)$ & $2(0.4)$ & \\
\hline Aortic valve insufficiency, n (\%) & $437(38.3)$ & $260(40.2)$ & $177(35.8)$ & 0.233 \\
\hline Mild & $340(29.8)$ & $209(32.4)$ & $131(26.5)$ & \\
\hline Moderate & $81(7.1)$ & $42(6.5)$ & $39(7.9)$ & \\
\hline Severe & $16(1.4)$ & $9(1.4)$ & $7(1.4)$ & \\
\hline Aortic valve stenosis, n (\%) & $87(7.6)$ & & & 0.118 \\
\hline Mild & $52(4.6)$ & $25(3.9)$ & $27(5.5)$ & \\
\hline Moderate & $9(0.8)$ & $5(0.8)$ & $4(0.8)$ & \\
\hline Severe & $26(2.3)$ & $20(3.1)$ & $6(1.2)$ & \\
\hline Mitral valve insufficiency, n (\%) & $541(47.5)$ & $322(49.8)$ & $219(44.3)$ & 0.135 \\
\hline Mild & $263(23.1)$ & $150(23.2)$ & $113(22.9)$ & \\
\hline Moderate & $254(22.3)$ & $154(23.8)$ & $100(20.2)$ & \\
\hline Severe & $24(2.1)$ & $18(2.8)$ & $6(1.2)$ & \\
\hline Mitral valve stenosis, n (\%) & $39(3.4)$ & $13(2.0)$ & $26(5.3)$ & 0.003 \\
\hline Mild & $18(1.6)$ & $9(1.4)$ & $9(1.8)$ & \\
\hline Moderate & $8(0.7)$ & $1(0.2)$ & $7(1.4)$ & \\
\hline Severe & $13(1.1)$ & $3(0.5)$ & $10(2.0)$ & \\
\hline Tricuspid valve insufficiency, n (\%) & $264(23.2)$ & $153(23.7)$ & $111(22.5)$ & 0.880 \\
\hline Systolic pulmonary artery pressure, $\mathrm{mmHg}$ & $20(15-30)$ & $22(15-30)$ & $18(20-30)$ & 0.776 \\
\hline Valvular vegetation, $\mathrm{n}(\%)$ & $2(0.2)$ & $1(0.2)$ & $1(0.2)$ & 0.677 \\
\hline Left ventricular thrombus, n (\%) & $5(0.4)$ & $5(0.8)$ & $0(0)$ & 0.074 \\
\hline Permeant pacemaker lead, n (\%) & $6(0.5)$ & $5(0.8)$ & $1(0.2)$ & 0.244 \\
\hline Pericardial effusion, $\mathrm{n}(\%)$ & $125(10.9)$ & $70(10.8)$ & $55(11.1)$ & 0.326 \\
\hline Mild & $114(10.0)$ & $65(10.1)$ & $49(9.9)$ & \\
\hline Moderate & $8(0.7)$ & $4(0.6)$ & $4(0.8)$ & \\
\hline Severe & $3(0.3)$ & $1(0.2)$ & $2(0.4)$ & \\
\hline
\end{tabular}


Table 3

Age-based distribution of CHDs of the study population

\begin{tabular}{|c|c|c|c|c|c|c|c|c|c|c|c|c|}
\hline $\begin{array}{l}\text { Age } \\
\text { category }\end{array}$ & $\begin{array}{l}\text { Non- } \\
\text { compaction } \\
n(\%)\end{array}$ & $\begin{array}{l}A S D \\
n(\%)\end{array}$ & $\begin{array}{l}A V C D \\
n(\%)\end{array}$ & $\begin{array}{l}P D A \\
n(\%)\end{array}$ & $\begin{array}{l}\text { Congenital } \\
\text { PS } \\
n(\%)\end{array}$ & $\begin{array}{l}\text { Dextrocardia } \\
n(\%)\end{array}$ & $\begin{array}{l}\text { ToF } \\
n(\%)\end{array}$ & $\begin{array}{l}\text { НCMP } \\
n(\%)\end{array}$ & $\begin{array}{l}\text { Myxoma } \\
n(\%)\end{array}$ & $\begin{array}{l}T G A \\
n(\%)\end{array}$ & $\begin{array}{l}V S D \\
n(\%)\end{array}$ & $\begin{array}{l}\text { Subaortic } \\
\text { membrane } \\
n(\%)\end{array}$ \\
\hline $0-15$ & $0(0)$ & $\begin{array}{l}25 \\
(2.2)\end{array}$ & $\begin{array}{l}5 \\
(0.4)\end{array}$ & $23(2.0)$ & $7(0.6)$ & $0(0)$ & $\begin{array}{l}15 \\
(1.3)\end{array}$ & $0(0)$ & $0(0)$ & $\begin{array}{l}8 \\
(0.7)\end{array}$ & $\begin{array}{l}18 \\
(1.6)\end{array}$ & $1(0.1)$ \\
\hline $16-30$ & $1(0.1)$ & $\begin{array}{l}8 \\
(0.7)\end{array}$ & $\begin{array}{l}1 \\
(0.1)\end{array}$ & $2(0)$ & $3(0.3)$ & $0(0)$ & $\begin{array}{l}4 \\
(0.4)\end{array}$ & $\begin{array}{l}4 \\
(0.4)\end{array}$ & $0(0)$ & $0(0)$ & $\begin{array}{l}5 \\
(0.4)\end{array}$ & $1(0.1)$ \\
\hline $31-45$ & $0(0)$ & $\begin{array}{l}1 \\
(0.1)\end{array}$ & $0(0)$ & $0(0)$ & $0(0)$ & $0(0)$ & $\begin{array}{l}1 \\
(0.1)\end{array}$ & $\begin{array}{l}1 \\
(0.1)\end{array}$ & $1(0.1)$ & $0(0)$ & $\begin{array}{l}2 \\
(0.2)\end{array}$ & $0(0)$ \\
\hline $46-60$ & $3(0.3)$ & $\begin{array}{l}2 \\
(0.2)\end{array}$ & $0(0)$ & $0(0)$ & $0(0)$ & $1(1)$ & $0(0)$ & $\begin{array}{l}4 \\
(0.4)\end{array}$ & $1(0.1)$ & $0(0)$ & $\begin{array}{l}1 \\
(0.1)\end{array}$ & $0(0)$ \\
\hline $61-75$ & $1(0.1)$ & $\begin{array}{l}1 \\
(0.1)\end{array}$ & $0(0)$ & $0(0)$ & $0(0)$ & $0(0)$ & $0(0)$ & $0(0)$ & $0(0)$ & $0(0)$ & $0(0)$ & $0(0)$ \\
\hline+75 & $0(0)$ & $0(0)$ & $0(0)$ & $0(0)$ & $0(0)$ & $0(0)$ & $0(0)$ & $0(0)$ & $0(0)$ & $0(0)$ & $0(0)$ & $0(0)$ \\
\hline Total & $5(0.4)$ & $\begin{array}{l}37 \\
(3.2)\end{array}$ & $\begin{array}{l}6 \\
(0.5)\end{array}$ & $25(2.2)$ & $10(0.9)$ & $1(0.1)$ & $\begin{array}{l}20 \\
(1.8)\end{array}$ & $\begin{array}{l}9 \\
(0.8)\end{array}$ & $2(0.2)$ & $\begin{array}{l}8 \\
(0.7)\end{array}$ & $\begin{array}{l}26 \\
(2.3)\end{array}$ & $2(0.2)$ \\
\hline
\end{tabular}

\section{Discussion}

To the best of our knowledge,this is the first echocardiographic study to evaluate comprehensively such a large cohort of patients in Somalia.Given inadequate healthcare services in Somalia, which is an active war zone, we consider that this study is of high value.In our investigation, HHD was the most frequent comorbidity (39.8\%), followed by degenerative valvular disease (34.6\%),HFrEF (\%30.8), and IHD (24.4\%),RHD (7.4\%).Additionally, $13.2 \%$ of the study population were diagnosed with CHD, with the most common being ASD, VSD, and PDA, respectively.

Somalia's total population is estimated at 15.4 million, of whom about 4.5 million are children under the age of 14 . Health institutions in Somalia often provide rather limited facilities for individuals with chronic illnesses and those in need of advanced care and unfortunately, no tertiary healthcare centers existin Mogadishu and surrounding provinces, except for the region where this study was conducted.All these deficiencies prevent timely diagnosis by appropriate detection modalities, increasing the likelihood of poor outcomes in such populations. Moreover, delayed hospital admission, advanced maternal age, high rates of consanguineous marriage, and the presence of many infectious diseases that have not been eradicated nationwide may result in an increased incidence and prevalence of both acquired and congenital heart diseases.Yet, unfortunately, there are very few studies in the literature reporting the risk factors, profile, and echocardiographic characteristics of the African population. For instance, in an echocardiographic study conducted in Nigeria, Ogahet al[12].detected HHD in 56.7\% of the patients. In another echocardiographic study,Raphael et al[13].evaluated 815 adults and 59 children aged $\leq 15$ years and reported that normal echocardiographic findings were detected in only $44 \%$ of the patients and that the most common comorbidities were HHD (41\%), VHD (18\%), coronary artery disease (18\%), and peripartum cardiomyopathy (7\%) in adults, while CHD were the most common comorbidities in children (34\%). In our study, HHD was the most common echocardiographic finding (39.8\%), which could be related to the excessive salt consumption by habitantsin this region and also to some other factors such as difficult and delayed diagnosis, inadequate medication,and insufficient follow-up.

Despite the decrease in the incidence of rheumatic fever/RHD over the last few decades, it remains an acquired health problem, especially in lowmiddle-income countries[14]. In an investigation conducted on patients with structural and functional valve abnormalities, $24 \%$ of the subjects had a valvular abnormality, with the most common abnormality being mitral valve insufficiency (59\%), and approximately one-third (36\%) of the patients were diagnosed with RHD[15]. In the present study,the most frequent valvular abnormality was mitral insufficiency(47.5\%),consistent with the former, and a high rate of RHD was diagnosed. As noted above, RHD is a vital health issue in many African countries, including Somalia, mostly due to inadequate healthcare in both diagnosis and treatment.Further comprehensive studies are needed to overcome this problem and raise social awareness and cultural knowledge. Additionally, it is an inevitable requirement to develop inadequate healthcare services and patient follow-up approaches to reduce the incidence of RHD associated with autoimmune pathophysiology.

The prevalence of CHDs is relatively similar worldwide, ranging from 4 to 85 per 1000 births[3, 16, 17]. Although VSD is generally the most common CHD, studies with a higher frequency of ASD have also been reported, which is compatible with ours[18, 19]. This discordance may be related to the following conditions; (i) inter-regional genetic variation, (ii) the overwhelming majority of the participants in our study population is adults and we acknowledge that some small VSDs might close spontaneously with age, and (iii) diagnosis by transthoracic echocardiography alone may cause some VSDs to be overlooked. Besides, factors such as excessive use of herbal medicines, alcohol-cigarette consumption, inadequate control of chronic diseases, and inadequate vaccination against infectious diseases may be associated with the high prevalence of 
CHDs in Somalia[20]. While the prevalence of CHDs in adults increases in developing countries nowadays, it is relatively less common in adults because of high morbidity and mortality in countries with many health system defects, such as Somalia.Similarly, in our study, we have reached a conclusion consistent with the former assumption by determining that $67.5 \%$ of individuals with $\mathrm{CHD}$ were 15 years or younger.

\section{Conclusion}

In the present study, we found that HHD was the most common comorbidity (39.8\%), followed by degenerative valvular disease (34.6\%), HFrEF (\%30.8), and IHD (24.4\%). Moreover, the most common valvular disease was mitral insufficiency (47.5\%) and the most common CHD was ASD (3.2\%). Further comprehensive studies with prospective design are warranted to improve the insufficient healthcare services and raise public awareness in Somalia, a war zone where financial and healthcare opportunities are highly limited.

\section{Abbreviations}

CVD: Cardiovascular diseases; HHD: Hypertensive heart disease; CHD: Congenital heart diseases; ASD : Atrial septal defect ; VSD: Ventricular septal defect ; PDA : Patent ductus arteriosus ; RHD: Rheumatic heart disease; EF: Ejection fraction ; IVS : Interventricular septum ; LV : Left ventricular ; VHD : Valvular heart disease ;IHD: Ischemic heart disease ; DCM : Dilated cardiomyopathy ; HCM : Hypertrophic cardiomyopathy ; PE : Pericardial effusion; HFrEF: Heart failure with reduced ejection fraction ; IQR: interquartile range.

\section{Declarations}

\section{Acknowledgements}

Not applicable.

\section{Authors' contributions}

GA carried out the studies, participated in collecting data, and drafted the manuscript.GA and ÖG performed the statistical analysis and participated in its design.GA participated in the acquisition, analysis, or interpretation of data and draft the manuscript. All authors read and approved the fnal manuscript.

\section{Funding}

Not applicable.

\section{Availability of data and materials}

The datasets used or/and analyzed during the current study are available from the corresponding author on reasonable request.

\section{Ethics approval and consent to participate}

The study was approved by the Independent Ethics Committee of Somalia Mogadishu Training And Research Hospital (Mogadishu, Somalia)

\section{Consent for publication}

Not applicable.

\section{Competing interests}

The authors declare that they have no competing interests.

\section{References}

1. Khairy P, lonescu-Ittu R, Mackie AS, Abrahamowicz M, Pilote L, Marelli AJ. Changing mortality in congenital heart disease. J Am Coll Cardiol. 2010;56(14):1149-57. Epub 2010/09/25.

2. Deaths by Cause, Age, Sex, by Country and by Region, 2000-2015. World Health Organization. 2016;In:2017(Organization WH. Global Health Estimates 2015:).

3. van der Linde D, Konings EE, Slager MA, Witsenburg M, Helbing WA, Takkenberg JJ, et al. Birth prevalence of congenital heart disease worldwide: a systematic review and meta-analysis. J Am Coll Cardiol. 2011;58(21):2241-7. Epub 2011/11/15.

4. Rheumatic Heart Disease: Overview, symptoms and treatment. Organization WH. 2020. 
5. Stewart KA, Navarro SM, Kambala S, Tan G, Poondla R, Lederman S, et al. Trends in Ultrasound Use in Low and Middle Income Countries: A Systematic Review. Int J MCH AIDS. 2020;9(1):103-20. Epub 2020/03/04.

6. Mitchell C, Rahko PS, Blauwet LA, Canaday B, Finstuen JA, Foster MC, et al. Guidelines for Performing a Comprehensive Transthoracic Echocardiographic Examination in Adults: Recommendations from the American Society of Echocardiography. J Am Soc Echocardiogr. 2019;32(1):1-64. Epub 2018/10/05.

7. Reményi B, Wilson N, Steer A, Ferreira B, Kado J, Kumar K, et al. World Heart Federation criteria for echocardiographic diagnosis of rheumatic heart disease-an evidence-based guideline. Nat Rev Cardiol. 2012;9(5):297-309. Epub 2012/03/01.

8. Pinto YM, Elliott PM, Arbustini E, Adler Y, Anastasakis A, Böhm M, et al. Proposal for a revised definition of dilated cardiomyopathy, hypokinetic non-dilated cardiomyopathy, and its implications for clinical practice: a position statement of the ESC working group on myocardial and pericardial diseases. Eur Heart J. 2016;37(23):1850-8. Epub 2016/01/23.

9. Williams LK, Frenneaux MP, Steeds RP. Echocardiography in hypertrophic cardiomyopathy diagnosis, prognosis, and role in management. Eur J Echocardiogr. 2009;10(8):iii9-14. Epub 2009/11/06.

10. Elliott PM, Anastasakis A, Borger MA, Borggrefe M, Cecchi F, Charron P, et al. [2014 ESC Guidelines on diagnosis and management of hypertrophic cardiomyopathy]. Kardiol Pol. 2014;72(11):1054-126. Epub 2014/12/20.

11. Bossone E, D'Andrea A, D'Alto M, Citro R, Argiento P, Ferrara F, et al. Echocardiography in pulmonary arterial hypertension: from diagnosis to prognosis. J Am Soc Echocardiogr. 2013;26(1):1-14. Epub 2012/11/13.

12. Ogah OS, Adegbite GD, Akinyemi RO, Adesina JO, Alabi AA, Udofia Ol, et al. Spectrum of heart diseases in a new cardiac service in Nigeria: an echocardiographic study of 1441 subjects in Abeokuta. BMC Res Notes. 2008;1:98. Epub 2008/10/30.

13. Raphael DM, Roos L, Myovela V, McHomvu E, Namamba J, Kilindimo S, et al. Heart diseases and echocardiography in rural Tanzania: Occurrence, characteristics, and etiologies of underappreciated cardiac pathologies. PLoS One. 2018;13(12):e0208931. Epub 2018/12/27.

14. Tibazarwa KB, Volmink JA, Mayosi BM. Incidence of acute rheumatic fever in the world: a systematic review of population-based studies. Heart. 2008;94(12):1534-40. Epub 2008/08/02.

15. Sliwa K, Carrington M, Mayosi BM, Zigiriadis E, Mvungi R, Stewart S. Incidence and characteristics of newly diagnosed rheumatic heart disease in urban African adults: insights from the heart of Soweto study. Eur Heart J. 2010;31(6):719-27. Epub 2009/12/10.

16. Bernier PL, Stefanescu A, Samoukovic G, Tchervenkov Cl. The challenge of congenital heart disease worldwide: epidemiologic and demographic facts. Semin Thorac Cardiovasc Surg Pediatr Card Surg Annu. 2010;13(1):26-34. Epub 2010/03/24.

17. Zühlke L, Mirabel M, Marijon E. Congenital heart disease and rheumatic heart disease in Africa: recent advances and current priorities. Heart. 2013;99(21):1554-61. Epub 2013/05/18.

18. Sun PF, Ding GC, Zhang MY, He SN, Gao Y, Wang JH. Prevalence of Congenital Heart Disease among Infants from 2012 to 2014 in Langfang, China. Chin Med J (Engl). 2017;130(9):1069-73. Epub 2017/05/05.

19. Sen SS, Barua T, Dey D, Chowdhury MA, Nessa L. Pattern of congenital heart disease in children presenting at paediatric cardiology unit in Chattagram Maa Shishu-O-General Hospital, Chittagong. Chattagram Maa-O-Shishu Hospital Medical College Journal. 2017;16(2):40-3.

20. Yusuf MF, Icen YK, Ahmed SA, Osman AA, Hussein AM. Frequency and Pattern of Congenital Heart Diseases Among Children in a Tertiary Hospital in Mogadishu, Somali, 2019: A Hospital-Based Study. Iranian Heart Journal. 2021;22(1):10-5.

\section{Figures}




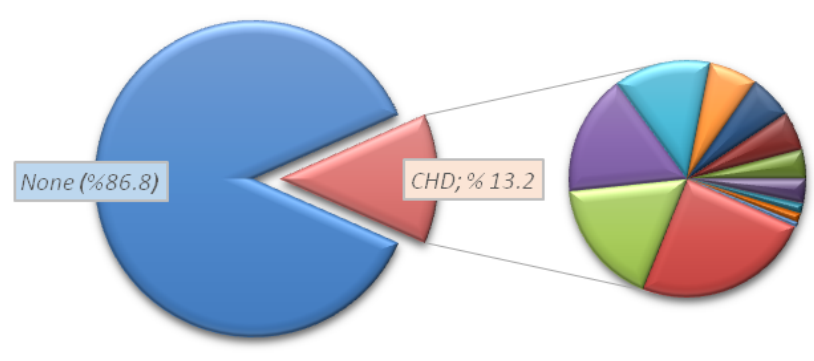
- None $(\% 86.8)$
\ASD (\%3.2)
口PDA(\%2.2)
๑ $\mathrm{ToF}(\% 1.8)$
DHCMP $(\% 0.8)$
- $\mathrm{TGA}(\% 0.7)$
- Non-compaction (\%0.4)
Myxoma $(\% 0.2)$
$\square$ Dextrocardia $(\% 0.1)$

$\square \operatorname{VSD}(\% 2.3)$

$\square$ Congenital PS (\%0.9)

aV canal defect $(\% 0.5)$

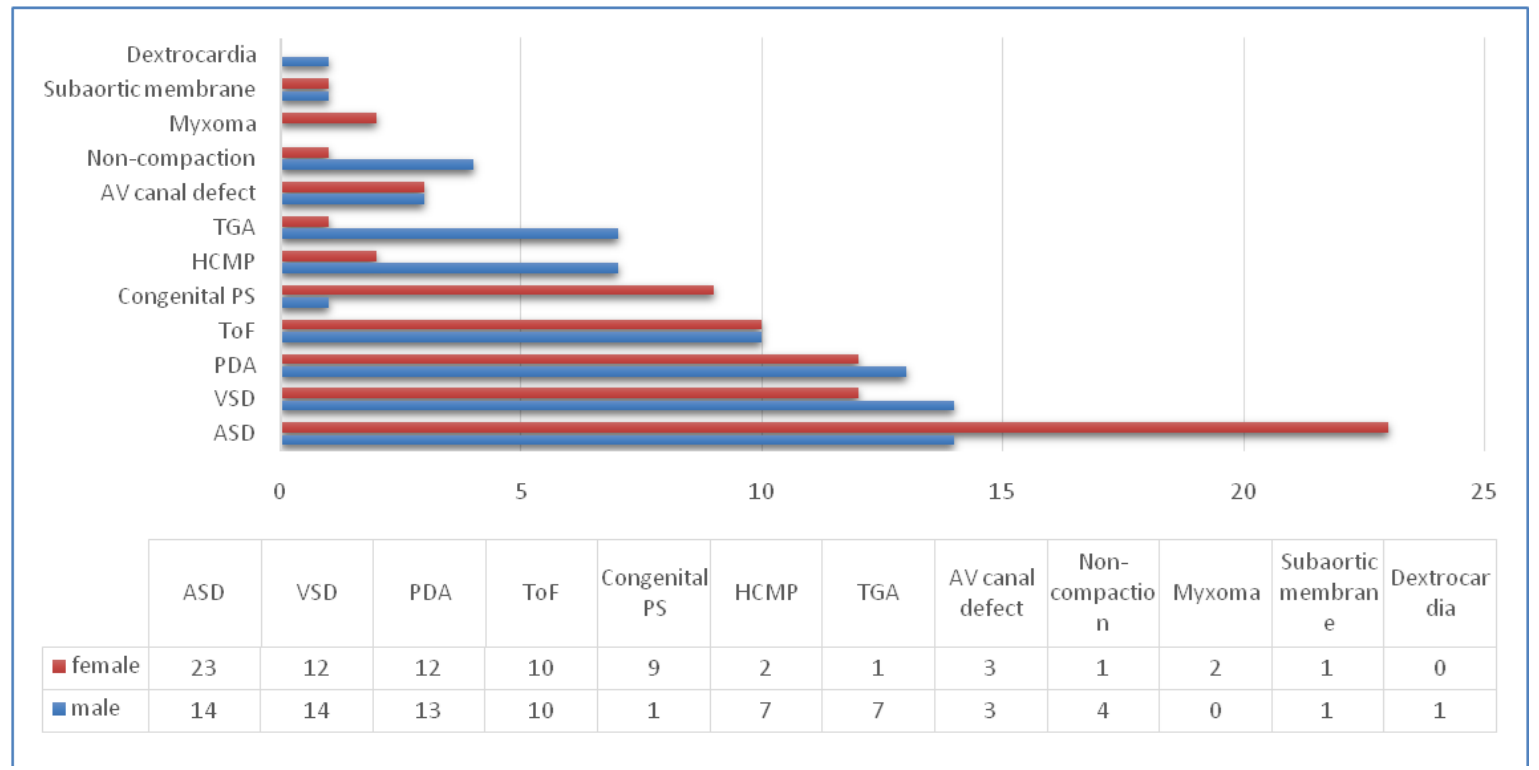

\section{Figure 1}

a: Distribution of various patterns of congenital heart diseases Abbreviations: PDA, Patent ductus arteriosus; HCMP, Hypertrophic cardiomyopathy; ASD, Atrial septal defect; VSD, Ventricular septal defect; ToF, Tetralogy of Fallot; TGA, Transposition of the Great Arteries; CHD, congenital heart disease b:Distribution chart of congenital heart diseases by gender Abbreviations: TGA, Transposition of the Great Arteries; HCMP, Hypertrophic cardiomyopathy; ToF, Tetralogy of Fallot; PDA, Patent ductus arteriosus; VSD, Ventricular septal defect; ASD, Atrial septal defect.

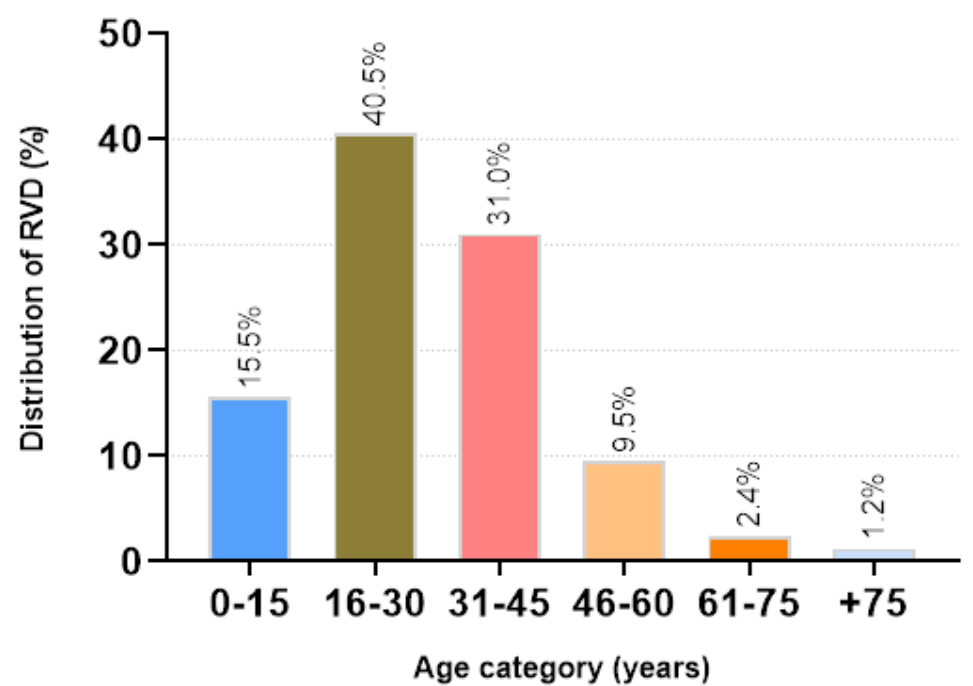


Figure 2

Distribution of rheumatic valvular disease by age category Abbreviations: RVD, Rheumatic valvular disease 